OPEN ACCESS

Edited by:

Martin Bojowald,

The Pennsylvania State University,

USA

Reviewed by:

Kazuharu Bamba,

Fukushima University, Japan

Zurab Silagadze,

Novosibirsk State University, Russia

*Correspondence:

F. Javier Medina

fjmedina@cib.csic.es

${ }^{\dagger}$ These authors have contributed equally to this work.

Specialty section:

This article was submitted to

Cosmology,

a section of the journal

Frontiers in Astronomy and Space

Sciences

Received: 07 December 2015

Accepted: 18 January 2016

Published: 05 February 2016

Citation:

Manzano Al, Herranz R, Manzano A, van Loon JJWA and Medina FJ (2016)

Early Effects of Altered Gravity

Environments on Plant Cell Growth and Cell Proliferation: Characterization of Morphofunctional Nucleolar Types in an Arabidopsis Cell Culture System.

Front. Astron. Space Sci. 3:2.

doi: 10.3389/fspas.2016.00002

\section{Early Effects of Altered Gravity Environments on Plant Cell Growth and Cell Proliferation: Characterization of Morphofunctional Nucleolar Types in
an Arabidopsis Cell Culture System}

Ana I. Manzano ${ }^{1+}$, Raúl Herranz ${ }^{1+}$, Aránzazu Manzano ${ }^{1}$, Jack J. W. A. van Loon ${ }^{2,3,4}$ and F. Javier Medina ${ }^{1 *}$

${ }^{1}$ Centro de Investigaciones Biológicas (CSIC), Madrid, Spain, ${ }^{2}$ Department of Oral and Maxillofacial Surgery/Oral Pathology, Dutch Experiment Support Center, VU University Medical Center, Amsterdam, Netherlands, ${ }^{3}$ Academic Centre for Dentistry Amsterdam (ACTA), Amsterdam, Netherlands, ${ }^{4}$ ESA-ESTEC, TEC-MMG, Noordwijk, Netherlands

Changes in the cell growth rate of an in vitro cellular system in Arabidopsis thaliana induced by short exposure to an altered gravity environment have been estimated by a novel approach. The method consisted of defining three structural nucleolar types which are easy and reliable indicators of the ribosome biogenesis activity and, consequently, of protein biosynthesis, a parameter strictly correlated to cell growth in this cellular system. The relative abundance of each nucleolar type was statistically assessed in different conditions of gravity. Samples exposed to simulated microgravity for 200 min showed a significant decrease in nucleolar activity compared to $1 \mathrm{~g}$ controls, whereas samples exposed to hypergravity $(2 g)$ for the same period showed nucleolar activity slightly increased. These effects could be considered as an early cellular response to the environmental alteration, given the short duration of the treatment. The functional significance of the structural data was validated by a combination of several different well-known parameters, using microscopical, flow cytometry, qPCR, and proteomic approaches, which showed that the decreased cell growth rate was decoupled from an increased cell proliferation rate under simulated microgravity, and the opposite trend was observed under hypergravity. Actually, not all parameters tested showed the same quantitative changes, indicating that the response to the environmental alteration is time-dependent. These results are in agreement with previous observations in root meristematic cells and they show the ability of plant cells to produce a response to gravity changes, independently of their integration into plant organs.

Keywords: nucleolus, simulated microgravity, hypergravity, cell growth, cell proliferation, electron microscopy

Abbreviations: $g$, acceleration of gravity; LDC, Large Diameter Centrifuge; RPM, Random Positioning Machine. 


\section{INTRODUCTION}

Plant development is modulated by environmental factors. Among them, gravity is the unique parameter that has remained constant on Earth throughout the entire history of life. All living organisms are well adapted to this $1 g$ level, which is used by plants to define their developmental pattern and to optimize the capture of light, water, and mineral salts. Consequently, the modification of this parameter would lead to significant physiological changes and would eventually trigger adaptive mechanisms. Understanding these changes is important for increasing our basic knowledge on plant physiology, but it is also essential for plant space biology, if we consider that gravity is one of the most important factors differentiating the Earth environment from the outer space or exoplanets. Plants will be essential for the coming enterprises of manned space exploration as part of the life support systems required to feed humans during long spaceflights and for survival on exoplanets. For this purpose, plants need to be adapted to grow in near-zero gravity (space) and in fractional gravity, e.g., on the Moon, where gravitational acceleration is $1 / 6 g$, or on Mars, where gravity is $3 / 8 g$.

The fact that the Earth $1 g$ level cannot be avoided on the surface of our planet makes necessary that experiments under real microgravity have to be done in outer space (freefall towers can provide a few seconds of weightlessness, not enough for most types of biological experiments). However, given the severe limitations in the access to spaceflights, even after the implementation of the International Space Station (ISS), a number of ground-based facilities have been developed, capable of providing a simulation of altered gravity environments (Herranz et al., 2013a). A reduced gravity environment can be simulated by $3 \mathrm{D}$ clinorotation on a random positioning machine (RPM, Dutch Space, Leiden, The Netherlands) (Van Loon, 2007) and increased gravitational load present in hypergravity habitats is obtained by centrifugation (Van Loon et al., 2008).

Since, as indicated above, gravity is used by plants to determine their developmental pattern, gravity alterations should have an effect on cellular processes which constitute the basis for plant development, such as cell proliferation and cell growth. Results obtained in a series of pioneering space and groundbased experiments, using lentil seedlings, showed significant alterations in cell cycle progression, in the mitotic index and in the duration of cell cycle phases, strongly suggesting that altered gravity produces modifications in the regulatory mechanisms of the cell cycle (Merkys et al., 1984; Darbelley et al., 1989; Legué et al., 1996; Yu et al., 1999; Driss-Ecole et al., 2008). More recently, we reported that Arabidopsis seedlings germinated and fixed after 4 days of growth in the International Space Station (ISS) showed a decoupling between the rates of cell proliferation (increased) and cell growth (decreased) (Matía et al., 2010). Subsequent experiments performed with seedlings on Earth by our group, using different devices for simulation of altered gravity conditions, have largely reproduced the results obtained in space. Clinorotation and diamagnetic levitation technologies have been used to reproduce a decoupling similar as observed in space under microgravity conditions, and somehow opposite in the case of centrifuges for the hypergravity environments (Manzano et al., 2012b, 2013).

In other experiments on meristematic root cells grown in simulated microgravity, a depletion of ribosome biogenesis was reported (Shen-Miller and Hinchman, 1995; Sobol et al., $2005,2006)$, but this finding was not connected to other cell functions. Furthermore, genomic and proteomic experiments with callus cell cultures of Arabidopsis thaliana in real and simulated microgravity, including microarray experiments, have also demonstrated alterations in genes and proteins involved in various processes, functions and cellular activities, some of them related to abiotic stress response and to cell cycle regulation (Barjaktarovic et al., 2009; Manzano et al., 2012a; Paul et al., 2012; Herranz et al., 2013b; Fengler et al., 2015).

The mechanisms of the cellular effects of gravity alterations on meristems are presently unknown in detail, but it is known that, in general, environmental signals transduced between different plant organs are capable of activating modulators of cell proliferation and cell growth in a coordinated manner in meristems; the reception of these signals and the response to them is called "meristematic competence" (Mizukami, 2001). Modulation of cell proliferation in meristems unequivocally refers to the regulation of cell cycle progression in the known checkpoints, which determines the rate of cell division (Inzé and De Veylder, 2006; De Veylder et al., 2007; Van Leene et al., 2010). With regards to cell growth, this concept in meristematic cells is meant for the production of cell biomass, essentially proteins, above a certain threshold compatible with cell division, which is subjected to a specific checkpoint (Mizukami, 2001; Doerner, 2008). Therefore, cell growth must be tightly coupled with proliferation, spatially as well as temporally, such that, if this coupling is disrupted, cells will lose meristematic competence. It should be stressed that an increase in the cell size can be achieved by other means, different from those operating in meristematic cells; for example, in postmitotic differentiating cells, mass increase is due to osmotically driven water uptake and cell enlargement coincides spatio-temporally with the development and expansion of vacuoles. In this case, strictly speaking, we should refer to "cell expansion," but not to "cell growth." The difference between these two processes is not semantic because they are driven by different mechanisms (Li et al., 2005; Doerner, 2008).

Consequently, meristematic cell growth is determined largely by the activity of the ribosome biogenesis and the protein synthesis (Bernstein and Baserga, 2004; Baserga, 2007; Bernstein et al., 2007). Ribosome biogenesis occurs in a well-defined nuclear domain, the nucleolus, whose structural features are a reliable marker of the rate of ribosome production (Sáez-Vásquez and Medina, 2008).

Furthermore, the structure of the nucleolus is highly sensitive to physiological alterations of the cell. Structural changes of the nucleolus are capable of being detected at both light and electron microscopy levels, as well as changes in the levels and location of nucleolar proteins, e.g., nucleolin. The fast and detectable response of the nucleolus to changes in the cell conditions is long known in different biological model systems, both animal and plant, and it is related to the key role played by the nucleolus in 
the functional activities of the cell (Srivastava and Pollard, 1999; Raska et al., 2006). In fact, the nucleolus and nucleolar activity have been identified as efficient and reliable indicators of cellular stress (Mayer and Grummt, 2005).

We have taken advantage of these features of the nucleolus to design an analytical method for detecting early functional changes in plant proliferating cells and to use it in the evaluation of the effects of altered gravity, with the objective of advancing in our knowledge of the alterations found in cell growth and proliferation. For this purpose, we have used an Arabidopsis semisolid cell culture system, taken as a reliable in vitro cellular model capable of verifying and extending our previous findings on cell growth and cell proliferation obtained in seedling root meristematic cells. To our knowledge, there is still not any relevant or significant information about the morphofunctional characterization of the nucleolus in in vitro cell cultures of Arabidopsis thaliana. Therefore, it was necessary to perform such this characterization and then to define structural types that could be interpreted from a functional point of view, according to the information that our laboratory had previously obtained in other plant systems, such as Allium cepa (González-Camacho and Medina, 2005).

Experiments under altered gravity conditions have been performed simultaneously in two facilities, namely the RPM (Random Positioning Machine), to simulate a microgravity environment, and the LDC (Large Diameter Centrifuge), to produce a $2 g$ environment, with the same set-up in the two facilities. A short treatment of $200 \mathrm{~min}$ was given in both conditions of altered gravity. This duration corresponds to approximately $15 \%$ of the duration of the cell cycle (Beemster and Baskin, 1998). Morphofunctional data obtained from nucleoli were validated by using a wide range of techniques including the analysis of cell cycle phases by flow cytometry, gene expression estimation of relevant factors affecting regulation of cell cycle and ribosome biogenesis (qPCR), and proteomic characterization of the key nucleolar protein nucleolin (2D-Western-blot). This collection of data allowed us to define cellular and molecular parameters involved in the early phase of response to gravity alteration and to discriminate them from parameters appearing unchanged in this phase. Indeed, a rapid initial response to the gravitropic stimulation, involving fast and transient changes in transcript levels throughout the first hour of gravity and mechanical stimulation has been described, followed by longerterm adaptive strategies (Moseyko et al., 2002; Kimbrough et al., 2004; Paul et al., 2012). The accurate identification of the parameters involved in this early response at the cellular and molecular level is important for the final goal of achieving a robust growth of plants in a microgravity environment, which is a novel condition for terrestrial organisms. Once these early changes had been identified, we will be in better conditions for investigating the adaptation strategies and mechanisms adopted to counteract the physiological alterations in order for the plant survival in the novel environment.

Additionally, our study has responded to the question on whether or not undifferentiated cells perceive gravity alterations in the absence of specialized tissue or organized developmental structures known to detect gravity.

\section{MATERIALS AND METHODS}

\section{Devices Mechanically Generating Altered Gravity Conditions (RPM and LDC): Descriptions and Setup}

We exposed samples to simulated microgravity in a Random Positioning Machine ( $\mu g-\mathrm{RPM}$, real random mode) and to hypergravity in the Large Diameter Centrifuge ( $2 g$-LDC) located at the European Space Research and Technology Centre (ESAESTEC) in Noordwijk, The Netherlands (Van Loon, 2007; Van Loon et al., 2008). The RPM run was performed using a real random mode with a maximum rotational speed of $60^{\circ} / \mathrm{s}$. In order to differentiate between the effects due to the mechanical load applied during 3D-rotation and centrifugation, we carried out the experiments simultaneously in the RPM and LDC, along with two external controls (one placed on the RPM static structure and the other within the central gondola at the rotational axis of the LDC). For both altered gravity conditions, the duration of the treatment was $200 \mathrm{~min}$, at RT (registered as $\left.22 \pm 0.5^{\circ} \mathrm{C}\right)$.

\section{Plant Materials and Growth Conditions}

Callus semi-solid cultures of Arabidopsis thaliana (cv. Landsberg erecta) were prepared from MM2d suspension cultures before a weekly refurbishment as described in previous literature (Menges and Murray, 2006). The biological material was grown in two regular $90 \mathrm{~mm}$ diameter Petri dishes as a $1-2 \mathrm{~mm}$ thick layer on the surface of a $1 \mathrm{~cm}$ layer of $1 \%(\mathrm{w} / \mathrm{v})$ agar with Murashige and Skoog's (MS) medium, where the suspension cultures were strewn on the agar surface 1 week before the start of the experiment. The cultures were protected from the light with aluminum foil coverage (darkness is the optimal growth conditions of the MM2d culture) and grown at $22^{\circ} \mathrm{C}$ to allow the callus to reach maximum density by the seventh day (1$2 \mathrm{~mm}$ thick layer). After RPM/LDC exposure, the samples were harvested and preserved immediately (less than $2 \mathrm{~min}$ ) by quick freezing in liquid nitrogen and subsequent dry ice storage. From each treatment, a small part of the culture was fixed in $3 \%(\mathrm{v} / \mathrm{v})$ glutaraldehyde in phosphate-buffered saline (PBS) for 5 days at $4^{\circ} \mathrm{C}$ for structural microscopical analysis.

\section{Sample Processing For Light and Electron Microscopy}

Samples fixed in $3 \%(\mathrm{v} / \mathrm{v})$ glutaraldehyde were transferred to PBS for washing (3 times, $10 \mathrm{~min}$ ), totally dehydrated in a methanol series (30-100\%, $30 \mathrm{~min}$ in each dilution), subjected to the methylation-acetylation procedure, a method allowing a better discrimination of nucleolar subcomponents (Testillano et al., 1995) and embedded in LR White resin (London Resin Co., London, UK). From the materials embedded in resin, semithin sections, $2 \mu \mathrm{m}$ in thickness, were cut and observed unstained under a Leica DM2500 microscope equipped with phase contrast. Images were digitally recorded with a Leica DFC320 CCD camera. For ultrastructural studies, ultrathin sections ( $\sim 60 \mathrm{~nm}$ thin), were mounted on Formvar-coated nickel grids, stained with $5 \%$ uranyl acetate for $30 \mathrm{~min}$, either alone 
or followed by $90 \mathrm{~s}$ in $0.3 \%$ lead citrate, and observed in a Jeol 1230 transmission electron microscope operating at $100 \mathrm{kV}$. Nucleolar quantitative measurements were carried out on digital images using the quantitation software "QWin Standard" (Leica Microsystems).

\section{Cell Cycle Analysis by Flow Cytometry}

One part of the frozen material was used for cell cycle analysis by flow cytometry. Samples were mixed with $500 \mu \mathrm{l}$ nuclear extraction buffer (Kit Cystain UV, precise P, Partec, Swedesboro, NJ, USA) (Menges and Murray, 2006) and were homogenized using an "Ultraturrax" blender (T25 basic; IKA Labortechnik, Staufen, Germany). The mixture was incubated during 2 min at room temperature and filtered through a double mesh with a pore of $50 \mu \mathrm{m}$ for cleaning the sample from cytoplasmic residues and organelles, keeping only intact nuclei in the extract. One $\mathrm{ml}$ of a fluorescent DNA marker solution including DAPI (kit Cystain UV precise $\mathrm{P}$ ) was added and staining proceeded for $2 \mathrm{~min}$ at room temperature. Then, samples were stored at $4^{\circ} \mathrm{C}$ in darkness. A maximum of $12 \mathrm{~h}$ later, the percentage of cells in each phase of cell cycle was estimated by analyzing the nuclear extracts of each sample in a Cell Sorter FACS (Vantage, Becton-Dickinson, San Diego, CA, USA), using a laser light with an excitation wavelength of $360 \mathrm{~nm}$. The results were analyzed with the ModFit Lt3.2 software (Verity Software House).

\section{RNA Extraction and Real-Time PCR}

Total RNA was extracted from three biological replicates of frozen calli using TRIzol reagent (Invitrogen/Life Technologies) according to the manufacturer's instructions and purified with DNase-turbo (Turbo DNA-free; AM1907 Ambion/Life Technologies,). RNA quantity and quality was first verified by gel electrophoresis and Nanodrop spectrophotometry. Purified RNA was used to made Quantified Retrotranscription-qPCR employing and following the Quantimix Easy SYG kit protocol (Biotools, Madrid, Spain) with a $30 \mathrm{~min}\left(48^{\circ} \mathrm{C}\right.$ RT step) followed by $10 \mathrm{~min}$ at $95^{\circ} \mathrm{C}$ (denaturalization step) and a 40 PCR cycles $\left(10 \mathrm{~s} 95^{\circ} \mathrm{C}, 20 \mathrm{~s} 60^{\circ} \mathrm{C}\right.$ and $\left.30 \mathrm{~s} 72^{\circ} \mathrm{C}\right)$. Probesets used are indicated in Table 1 . The results were processed by IQ5 Optical System Software (BioRad Laboratories). The same RNA samples were also used in a whole genome microarray analysis already available at GEO:GSE29787 (Manzano et al., 2012a).

\section{Protein Precipitation, Quantifications, 2D-Electrophoresis and Western-Blot}

Protein was extracted from three biological replicates as described (Barjaktarovic et al., 2007) and purified by methanol/chloroform precipitation. 2D-electrophoresis was carried out using the PROTEAN IEF system (BioRad) with $7 \mathrm{~cm}$ strips ("ReadyStripIPG," BioRad Laboratories), following instruction of the commercial mark. Two gels per sample were run; one of them was marked using SYPRO Ruby protein gel stain and the second gel was transferred to $0.20 \mu \mathrm{m}$ PVDF membrane by using the BioRad system for $1 \mathrm{~h}$ at $100 \mathrm{~V}$. Westernblot was done using anti-AtNUC-L1 (p) 1:2000. this is an antibody raised against "GAR," C-terminal region, which was kindly supplied to us by Dr. J. Saéz-Vásquez, University of Perpignan, France (Sáez-Vásquez et al., 2004; Pontvianne et al., 2007). The membrane was incubated with this primary antibody for $1 \mathrm{~h}$, and then with a second antibody (anti-rabbit linked to peroxidase activity for ECL, Amersham, GE Healthcare), at a dilution of 1:5000, for $1 \mathrm{~h}$. The peroxidase activity was developed by ECL solutions (ECL Western-blot Detection, Amersham, GE Healthcare).

\section{Statistical Analysis}

Statistical analysis of the data was performed using Stargraphic 5.1 software. Quantitative variables were assessed using mean and standard deviation values after checking normality with the Kolmogorov-Smirnov test. Mean values were compared using the Student $t$-test for independent samples; differences were considered significant for a bilateral value lower than 0.05 .

\section{RESULTS}

\section{Defining Morphofunctional Nucleolar Types}

The structural study was done on samples obtained from experiments performed in two mechanical devices for generation of altered gravity, namely RPM (simulated microgravity) and LDC (hypergravity) and their respective controls.

For simulated microgravity, the RPM is the most advanced and most commonly used model of 3D-clinostats or clinostats

TABLE 1 | RT-qPCR probeset list.

\begin{tabular}{|c|c|c|}
\hline Gene & Forward probe $\left(5^{\prime}-3^{\prime}\right)$ & Reverse probe $\left(5^{\prime}-3^{\prime}\right)$ \\
\hline CDKB1;1 (AT3G54180) & ACA AAG CGA TGG AGA AAG GA & CGA AGA GCA GTT GGT GGA AT \\
\hline СycB1;2 (AT5G06150) & GTG CCT TGC TTA TTG CTT CC & ATT GCC TTC TCC ATC ACC AG \\
\hline AtNucL1 (AT1G48920) & CCG AGA GGA GAT AGC AGT GG & TCC ACG ACC ACG ATC ACT T \\
\hline AtFib1 (AT5G52470) & CGT CTT TCG TTC TTC ACT TाT AGA CAA G & GCC CAC TAC GGC CTC TGT CA \\
\hline
\end{tabular}

All oligonucleotides used in RT-qPCR are listed, including the homeostatic control gene (actin) that shows no variations in any of the conditions analyzed and it was used to normalize the qPCR results. 
with two axes. A clinostat is a device in which samples are rotated to prevent the biological system from perceiving the gravitational acceleration vector, reaching the so-called "functional weightlessness" (Klaus et al., 1997). By means of fast and constant rotation, sedimentation is prevented physically by a continuous and constant change of the direction of the gravity vector. In the RPM, the quality of simulation is increased by rotating around two axes following a randomized speed profile, compared with a classic 2D-clinostat, especially for large objects (Kraft et al., 2000; Van Loon, 2007). These 3D-systems have two independently rotating frames; both frames can be operated with different speeds and different directions. With random mode setting the individual frame speed and the rotation direction are randomly varied, resulting in an unpredictable and symmetrical path (Borst and Van Loon, 2009). Main limitation of this technology is sample size, since centripetal accelerations appear as long as we place the sample far from the rotation center, especially when using high rotation speed (Van Loon, 2007).

For generation of hypergravity conditions, there are a large number of centrifuges available for the biological research community. A Large Diameter Centrifuge (LDC) has been developed by European Space Agency (ESA), allowing the acquisition of measurement points in the range from 1 to 20 g. This instrument can indeed provide a stable hypergravity environment for fundamental research on cells, plants and small animals (Van Loon et al., 2005).

The specific features of the two mechanical devices made necessary to perform a dedicated $1 g$ control experiment for each one of them, in order to separate the effects of the gravity alteration from possible effects due to the environmental conditions existing in the respective facilities. In all cases, the differences observed between these multiple $1 g$ control experiments were not statistically significant, thus validating the variations found in different gravity conditions.

As a first approach, nucleolar size was quantified in $2 \mu \mathrm{m}$ semithin sections observed by phase-contrast microscopy. This section thickness is in the range of the average diameter of the nucleolus in meristematic cells of Arabidopsis (Matía et al., 2010), which minimizes the chance of incorporating tangential sections into the accounts. This parameter provides an overall estimation of nucleolar activity (i.e., the rate of ribosome production) and, consequently, of cell growth. In general, the nucleolus was larger in hypergravity conditions compared to its rotational control. On the contrary, in simulated microgravity conditions the nucleolar size decreased compared to the $1 g$ control of the RPM experiment (Figure 1).

After this initial data, we investigated with higher detail the changes occurred in the nucleolus as a consequence of the alteration of the environmental gravity, in order to exploit the potentiality of this nuclear organelle as a reliable sensor of changes in cell physiology. For this purpose, we attempted the identification of nucleolar structural types that could serve as indicators of different functional states. The observations under the transmission electron microscope led us to the definition of three types, which can be called, according to their morphology, as "vacuolated," "compact," and "fibrillar" (Figure 2 shows representative examples of them in the gravitational conditions under study).

Vacuolated nucleoli are characterized by the presence of one or a few large and clear central spaces, which were called "nucleolar vacuoles" (Moreno Díaz De La Espina et al., 1980), that contain granules similar to the granular component of the nucleolus (Figure 2, upper row). The fibrillar centers, dense fibrillar component and granular component can be identified in the cortex, around the "vacuole." Functionally, vacuolated nucleoli appear in actively proliferating cells with high rate of production of ribosomal precursors (Risueño and Medina, 1986). Specifically, they are typical of cells found in the G2 cell cycle period, the most active in producing ribosomes (GonzálezCamacho and Medina, 2006).

The "compact" nucleoli apparently have a more homogeneous structure. Internal clearer spaces are fibrillar centers, zones for
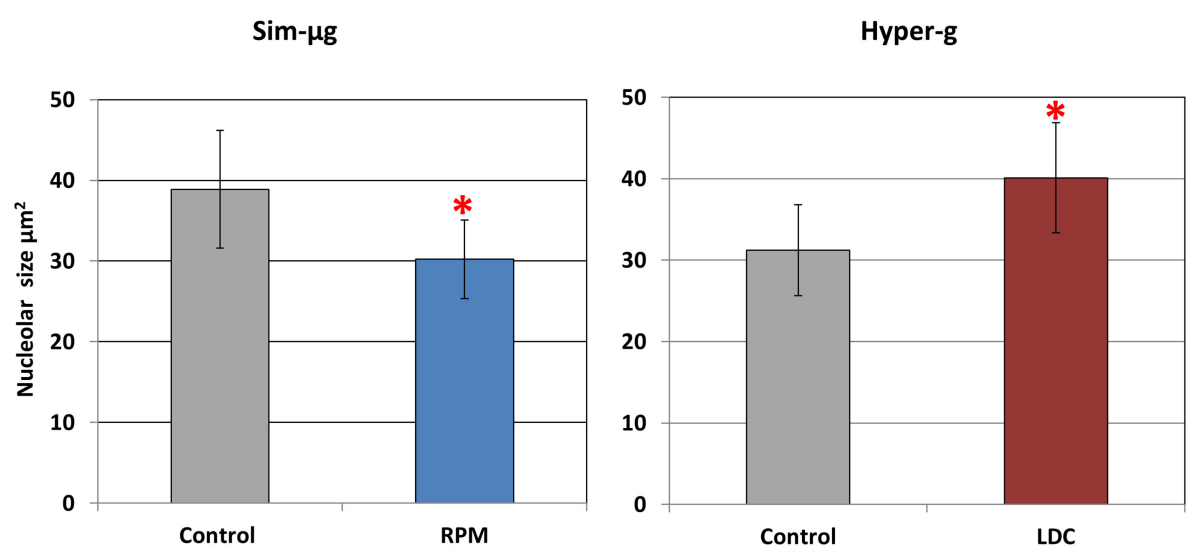

FIGURE 1 | Gravity related variations in the size of the nucleolus (mean $\pm \mathbf{S D} \boldsymbol{n}=\mathbf{6 0}$ ). Altered gravity produces significant variations, indicated by * $(p<0.05$ in the experimental condition vs. the respective $1 \mathrm{~g}$ control after Student $t$-test) in the area of the nucleolus, taken as a reliable marker of nucleolar activity in a proliferative cell system. Areas were measured on light microscopy images of semithin sections ( $2 \mu \mathrm{m}$ thick) of callus cultures. Simulated microgravity (sim- $\mu \mathrm{g})$ (RPM) induces a $19 \%$ reduction in the nucleolar area, while a $2 g$ environment (hyper-g) (LDC) produces larger nucleoli, with a $25 \%$ increase in this parameter. 


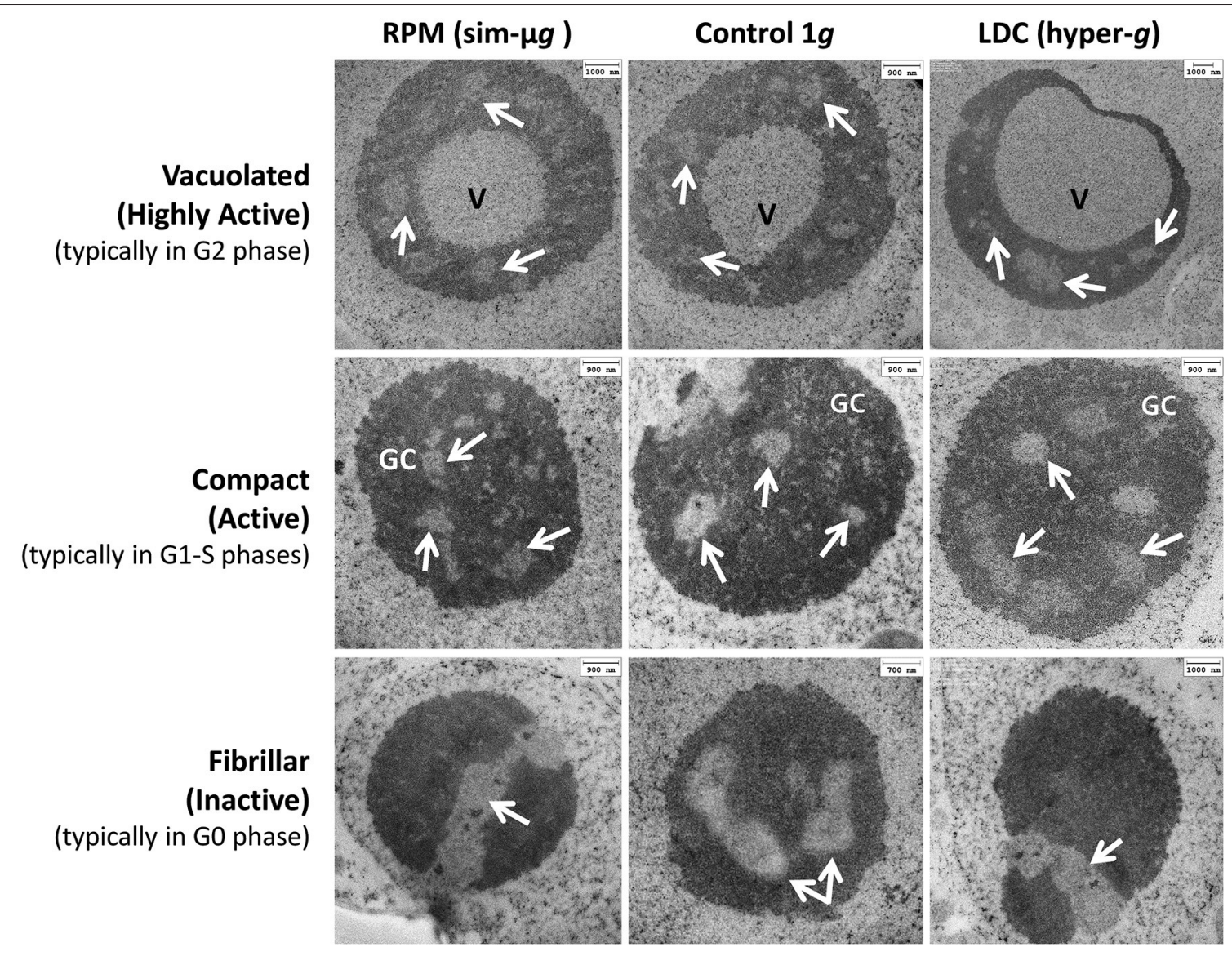

FIGURE 2 | Nucleolar morphofunctional types. Three structural types of nucleoli (in rows, Vacuolated, Compact and Fibrillar) have been characterized by electron microscopy in the three gravitational conditions [in columns, simulated microgravity (RPM), $1 g$ control and $2 g$ (LDC)]. Each morphological type shows a distinct amount and distribution of the nucleolar subcomponents, and can be associated with a differentiated level of nucleolar activity as well as, preferentially, with a period of the cell cycle. All types can be found in all conditions, although in different proportions. V, nucleolar "vacuole"; GC, granular component, arrows, fibrillar centers. Scale bars are indicated.

anchoring and accumulation of ribosomal chromatin, in which the complex of transcription by RNA polymerase I is organized (Sáez-Vásquez and Medina, 2008). The number and size of the fibrillar centers correlates with nucleolar activity. The dense fibrillar component is located around fibrillar centers, and further out, the granular component can be identified (Figure 2, central row). The compact nucleoli appear in proliferating cells with a variable activity of ribosome production, corresponding to the cell cycle periods G1 and S. The degree of nucleolar activity is correlated to the number and morphometric characteristics of the fibrillar centers, the nucleolar size and the proportion of granular component; the greater these parameters are, the more active is the nucleolus (Sáez-Vásquez and Medina, 2008).

Finally, the "fibrillar or inactive nucleoli" are characterized by the presence of a single large fibrillar center, which extends from side to side of the nucleolus although it may appear in sections as multiple, due to the effect of sectioning a meandering structure. Remarkably, small masses of condensed chromatin appear in its interior. Nucleolar mass is very compact, exclusively consisting of dense fibrillar component (Figure 2, lower row). These nucleoli were initially described in quiescent onion root meristems, functionally arrested due to the lack of water. The progress of the cell cycle in these cell types is stopped in the G0 period, a temporary or permanent period originated either from G1 or G2 (Risueño and Medina, 1986).

\section{Validation of the Nucleolar Types under Altered Gravity: Nucleolar Activity}

The nucleolar morphofunctional types, once identified and characterized under the electron microscope, could be easily identified by means of phase-contrast microscopy, by paying attention to their size and/or to their overall structural features (Figures 3A,B). We quantified the nucleolar classes in $65-80$ cells from each one of altered gravity conditions and their respective controls. Specifically, under simulated microgravity in the RPM there was a strong decrease in the number of cells with compact nucleoli and an even higher increase in inactive fibrillar nucleoli, but there were no significant changes in the proportion of vacuolated nucleoli, compared to the $1 \mathrm{~g}$ 

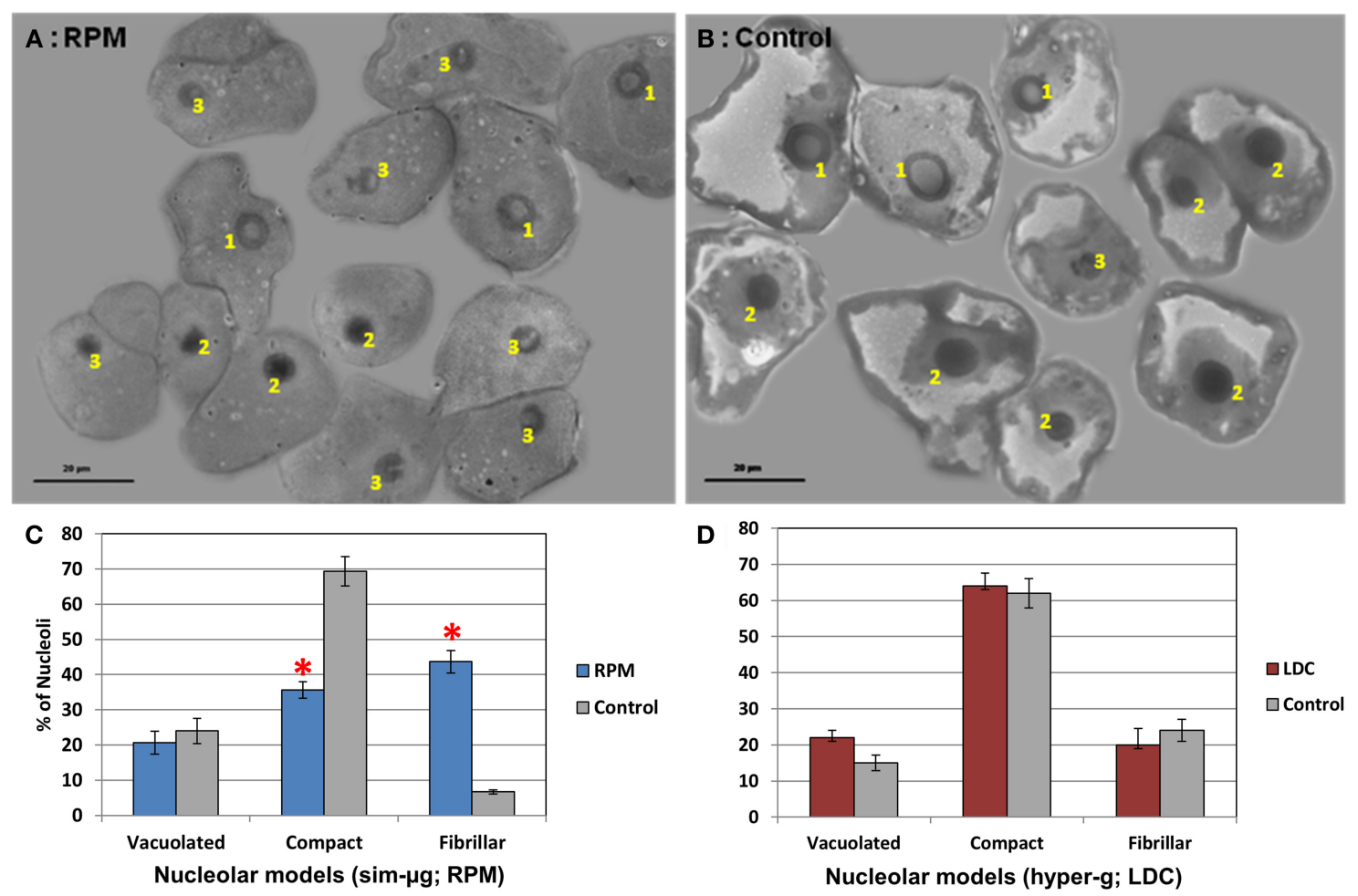

FIGURE 3 | Gravity-related variations in the proportion of the different nucleolar types. Nucleolar morphofunctional types were identified in optical microscope preparations of callus cultures grown in different conditions of gravity. (A) RPM sample, (B) $1 \mathrm{~g}$ control sample of the RPM experiment. In these images, 1 means vacuolated nucleoli, 2 means compact nucleoli and 3 means fibrillar nucleoli. The number of nucleoli belonging to each type was counted (mean \pm SD $n=65-80$ cells/preparation). (C) Percentage of each nucleolar type in simulated microgravity (RPM) and the corresponding $1 g$ control. Simulated microgravity produces an important decrease in the number of compact (active) nucleoli in favor of fibrillar (inactive) ones. (D) Percentage of each nucleolar type in $2 g$ hypergravity (LDC) and the corresponding $1 \mathrm{~g}$ control. The variation is slight but with the opposite trend (decrease of inactive nucleoli in favor of vacuolated/very active ones). Significant differences (Student $t$-test, $p<0.05$ ) are expressed by *

control (Figure 3C). This result was consistent with a decreased nucleolar size (Figure 1) and could be interpreted as a decline in nucleolar activity due to gravitational stress which was structurally detectable at an early stage of growth in the RPM. By contrast, the effect of hypergravity in the LDC was a significant increase in the nucleolar size, a parameter correlated with nucleolar activity (Figure 1), although, in this case, it was not reflected in significant differences in the proportion of the different nucleolar types compared to the rotational control (Figure 3D). Certainly, the raw data showed more vacuolated and compact nucleoli and less fibrillar nucleoli in hypergravitygrown samples than in the controls, but the differences were not statistically significant (Figure 3D).

Given the strict correlation existing in undifferentiated proliferating cells between nucleolar activity, rate of ribosome production, rate of protein synthesis and cell growth (Bernstein and Baserga, 2004; Baserga, 2007; Bernstein et al., 2007) we checked whether or not these structural changes in the nucleolus were associated with a detectable change of the cell size. The quantitative measurement did not indicate statistically significant differences in cell size between any of the altered gravity treatments and the respective $1 g$ controls in our experimental conditions (data not shown).

\section{Validation of the Nucleolar Types under Altered Gravity: Cell Cycle Phases}

The cell cycle status of the callus culture population was determined by quantifying DAPI-stained DNA by flow cytometry in the different gravitational environments. Even though the duration of the altered gravity treatment was less than $15 \%$ of the duration of the cell cycle, we could observe significant changes in cultures grown under simulated microgravity, specifically an increase in the percentage of cells in $S$ phase and subsequent increase of the G2/M population due to a highly significant decrease of G1 population (Figure 4). Interestingly, G1 is a period much longer than S and G2 in proliferating cells of Arabidopsis, so that this period was the major target of the altered gravity treatments. Therefore, a reduction in the proportion of cells in G1 phase could be interpreted as a shortening of this period and, consequently, as a shortening of the overall duration of the cell cycle under simulated microgravity conditions. A shorter cell cycle would mean a higher frequency of cell divisions, i.e., an increase of the cell proliferation rate. On the other hand, the hypergravity treatment seemed to cause non-significant alterations in the cell cycle phases distribution between $2 g$ and rotational conditions. However, a slight increase in the $S$ 
RPM (sim- $\mu g)$
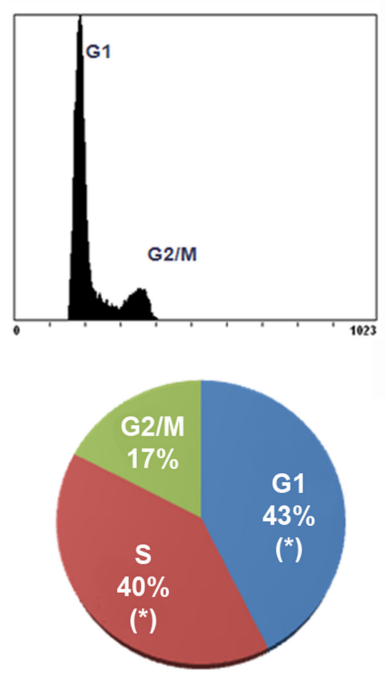

Control 19

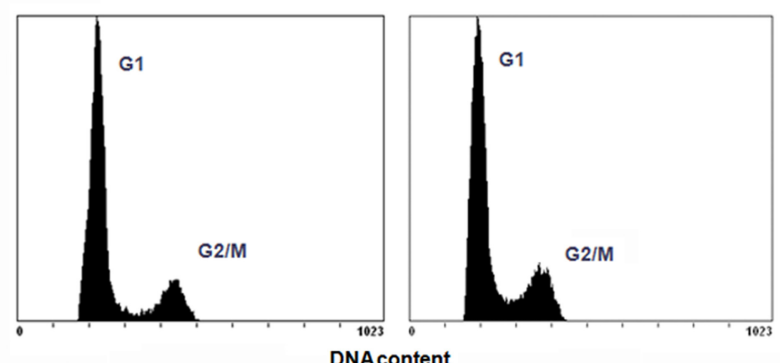

DNAcontent

LDC (hyper-g)
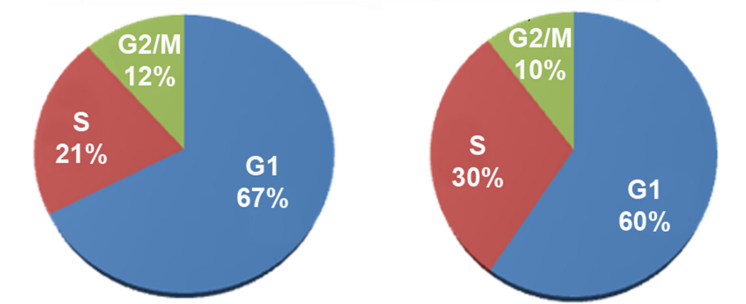

FIGURE 4 | Gravity-related variations in the subpopulations of cells in each cell cycle phase. Changes in the proportion of cell cycle phases in samples grown under different conditions of gravity were assessed by flow cytometry after DAPI-staining of DNA in cell cultures. The number of events ( $y$-axis) vs. the DNA content (DAPI signal in the x-axis) in the upper graph and its quantification in the lower pie charts are shown for each gravitational condition (10,000 cells counted from three replicates). Significant differences (Student $t$-test, $p<0.05$ ) are expressed by *. There was a significant decrease in the number of $\mathrm{G} 1$ cells in favor of $\mathrm{S}$ and G2/M cells under simulated microgravity. Taking into account that G1 is much longer than S and G2 phases, a shortening of the duration of the cell cycle under simulated microgravity conditions can be inferred from this result and, consequently, an acceleration (increase) of the cell proliferation rate. On the contrary, only slight variations were found in the hypergravity samples.

population and a decrease in the $\mathrm{G} 2 / \mathrm{M}$ population were noticed (Figure 4).

\section{Validation of the Nucleolar Types under Altered Gravity: Rt-qPCR}

Two genes involved in cell cycle regulation ( $\mathrm{CdkB} 1$ and cyclin B1) and two genes encoding major nucleolar proteins, namely nucleolin L1 and fibrillarin, taken as cell growth markers, were studied by retrotranscription quantitative PCR using samples grown in altered gravity produced by the RPM and LDC mechanical devices. In particular, the cyclin B1 gene is a marker of $\mathrm{G} 2 / \mathrm{M}$ transition of the cell cycle; this gene is expressed throughout the G2 period and the product is specifically destroyed in anaphase. Therefore, the expression of the cyclin B1 gene is considered a good marker of cell division, indirectly indicating the rate of entry into mitosis (ColónCarmona et al., 1999). Nucleolin L1 (AtNuc-L1) and fibrillarin are major nucleolar proteins, which play key roles in the regulation of ribosome biogenesis, and, in addition, their expression is in part regulated during cell cycle (González-Camacho and Medina, 2004, 2005) and plant development (Petricka and Nelson, 2007). In addition to the results obtained from qPCR experiments, we have incorporated the data on these genes obtained from a previous microarray experiment (Manzano et al., 2012a).

At the time of the altered gravity treatments, cell proliferation gene markers (those related to cell cycle regulation) showed a decreased expression level in simulated microgravity and an increase in hypergravity, compared to their respective controls, reaching statistical significance in $\mathrm{qPCR}$ experiments involving the cyclin B1 gene (Figure 5, first row). Strikingly, gene markers related to regulation of ribosome biogenesis/cell growth showed very small variations in our experimental conditions. Although microarray-extracted expression profiles were not significant, an increase in cell-growth-related genes was observed when analyzing qPCR results (Figure 5, second and third row).

\section{Validation of the Nucleolar Types under Altered Gravity: 2D-Western-Blot with Anti-AtNUC-L1 Antibody}

In order to further characterize the relationship between nucleolin gene expression, the functional role played by this protein and the structure and activity of the nucleolus during the early response of proliferating cells to altered gravity, we analyzed the electrophoretic mobility pattern of nucleolin isoforms by means of a bidimensional electrophoresis approach, followed by Western blotting. We paid attention to the span of the signal corresponding to this protein throughout the $\mathrm{pH}$ range in the 2-D Western blot, as a reliable estimation of the abundance of isoforms showing different levels of phosphorylation, as it was shown previously (González-Camacho and Medina, 2004), an also to the presence of spots at a level of apparent molecular weight lower than the main signal, indicative of proteolysis. The results obtained in both facilities of altered gravity showed opposite trends (Figure 6). In simulated microgravity conditions, the nucleolin-L1 isoforms showed a shorter span, consistent with the presence of less phosphorylation variants, as well as less proteolysis (50 and $30 \mathrm{kDa}$ apparent molecular weight); all these data are compatible with a lower activity of the protein 


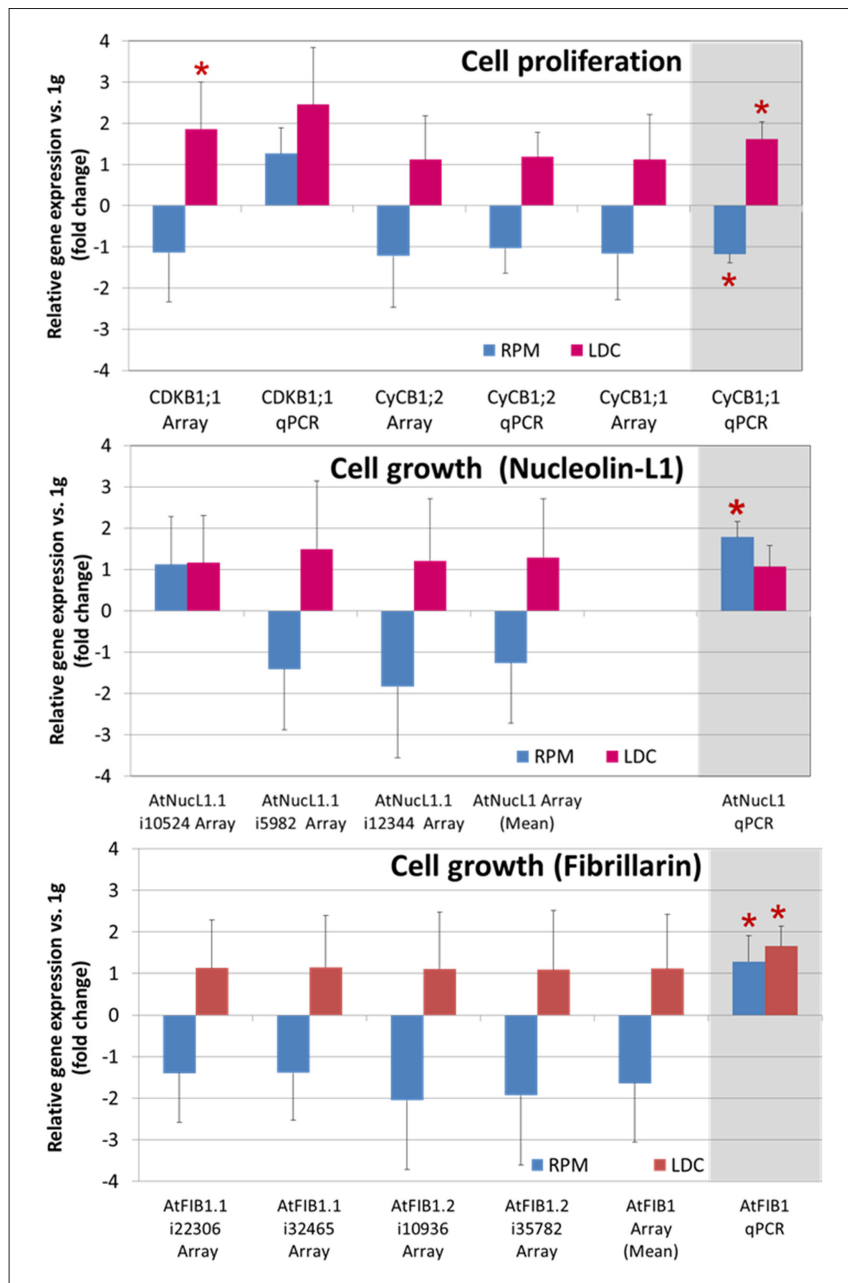

FIGURE 5 | Gravity-related variations in gene expression of cell proliferation and cell growth factors. Several genes known to be reliable markers of cell proliferation (cell cycle) and cell growth (ribosome biogenesis) have been analyzed as to their expression level in different conditions of gravity, using microarray probesets (GEO:GSE29787, Manzano et al., 2012a and RT-qPCR). Upper chart shows genes related to cell cycle regulation, and central and lower charts show genes coding for the nucleolar proteins nucleolin-L1 and fibrillarin (note that more than one probeset pair is available for those genes in the same microarray), respectively. In general, an opposite behavior has been found in simulated microgravity and hypergravity conditions vs. $1 \mathrm{~g}$ control. The most relevant $\mathrm{qPCR}$ results appear emphasized on the right column, shadowed in gray. Statistically significant results (Student $t$-test, $p<0.05$, RPM/LDC relative expression vs. $1 g$ control) are shown with an asterisk.

in the regulation of pre-rRNA processing. However, in LDC, a wider span, compatible with more phosphorylation variants or isoforms, as well as more proteolysis were shown, compared to $1 g$ (control LDC). These results were in agreement with a higher activity of the protein (González-Camacho and Medina, 2005, 2006).

\section{DISCUSSION}

Altered gravity conditions produce a decoupling of the cell growth and cell proliferation processes in root meristematic cells of seedlings (Matía et al., 2010; Manzano et al., 2012b, 2013). The results described here after simulated microgravity treatment in the RPM (depletion of cell growth and enhancement of cell proliferation) confirm the same effects found on seedlings, now using an in vitro cellular system characterized by high proliferation rates, and show that these effects can be detected shortly after the environmental change, although not all tested parameters related to these cellular functions appear equally modified. Regarding hypergravity $(2 g)$, the cellular system is also altered in the opposite direction and, in general, with intensities lower than under simulated microgravity.

These results were possible after the definition of a set of structural features in the nucleolus which are known to be correlated to the rate of ribosome biogenesis and which can then be used to easily determine under the microscope the actual state of the cell growth function in proliferating cells. The use of the nucleolar structural types has proven to be highly effective, showing clear differences between the different conditions analyzed, especially regarding the simulated microgravity treatment. Our results show once more that the nucleolus is an excellent sensor of the functional state of the cell and a reliable marker of the cellular stress, as it was previously reported (Srivastava and Pollard, 1999; Mayer and Grummt, 2005; Raska et al., 2006; Sáez-Vásquez and Medina, 2008). Furthermore, the system of evaluation of the nucleolar structural patterns presented here is not only applicable in the context of altered gravity research, but also in any other kind of plant cell study of changes induced by altered growth conditions on actively proliferating cells. The usefulness of a test that can quickly provide data on the growth/proliferation status of a cell population when exposed to a certain environmental stress, including pathological situations, is worth noting.

The results of our experiments have revealed that alterations in the regulatory mechanisms of the cell cycle are part of the early cellular response to gravitational stress. Gene expression changes in regulatory factors were in agreement with results reported on root meristematic cells from seedlings (Manzano et al., 2009, 2012a). In addition to the results included in Figure 5, Data Sheet 1 collects the list of dozens of cell-cycle-related genes that show altered expression levels in a microarray analysis with the same samples (Manzano et al., 2012a). Moreover, flow cytometry data have revealed changes in the duration of cell cycle phases, particularly an increase in both $\mathrm{S}$ and G2/M subpopulations of cells under simulated microgravity and small variations (even a decrease of $\mathrm{G} 2 / \mathrm{M}$ subpopulation) in the centrifuge. Otherwise, the decrease in the proportion of G1 cells, observed in the RPM samples, is compatible with the acceleration of cell cycle, resulting in the enhancement of the cell proliferation rate. It is important to remark that the short period of exposure to altered gravity conditions is probably not long enough to observe a defined effect on the duration of cell cycle phases, which becomes more evident after longer exposures to altered gravity (unpublished results). Whereas the short exposure to hypergravity conditions produces an extensive deregulation at the level of gene expression, the effects at the level of the duration of cell cycle phases, detectable by flow 

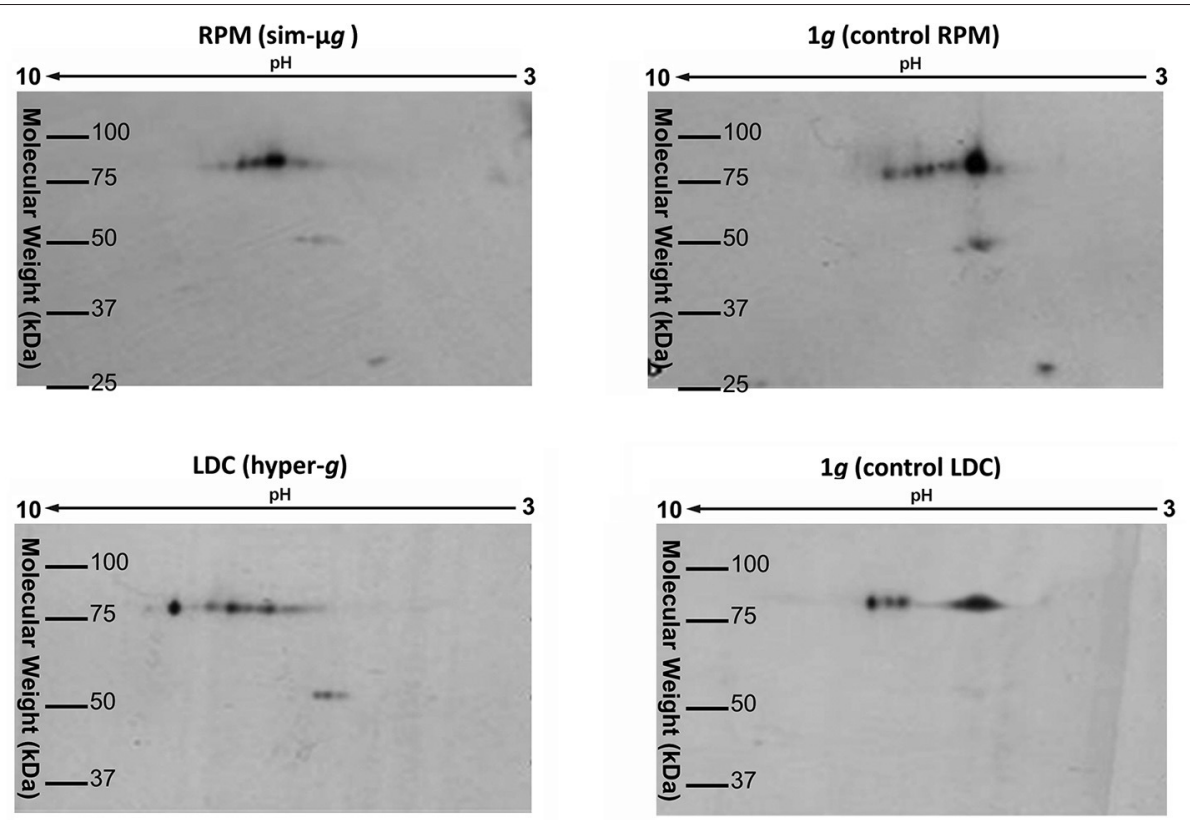

FIGURE 6 | Gravity-related variations in the isoelectric point of variants of the nucleolar protein nucleolin-L1. Experiments of 2D-Western blotting have been performed to determine the whole repertoire of variants (same molecular weight, different isoelectric point) of the essential nucleolar protein nucleolin- $L 1$ in different conditions of gravity. According to previously published results, these variants reflect different phosphorylation states of the protein and the number of variants (the span of spots through the $\mathrm{pH}$ range) is correlated to the nucleolin activity and to the rate of ribosome biogenesis (González-Camacho and Medina, 2004).

Nucleolin-L1 variants are increased in hypergravity conditions and decreased in simulated microgravity with respect to the respective $1 g$ controls.

cytometry, are still scarce and poorly defined in this early phase of response.

The results on the expression levels of cell growth regulatory genes are relatively uncertain. While AtNUC-L1 and AtFIB, proteins involved in ribosome biogenesis (Cerdido and Medina, 1995; Medina et al., 2000), showed a slight increase in gene expression under both altered gravity conditions by RTqPCR, previous data obtained from microarray experiment were different and more consistent with the results obtained from the structural study of nucleoli (decreased in simulated microgravity but increased in hypergravity), although the magnitude of the detected changes was always small. However, the results at the protein level were more convincing. On 2DWestern-blots, nucleolin-L1 isoforms showed a reduced span of isoelectric point in the RPM, the same as it was found in root meristematic cells (Matía et al., 2007), and this span was wider in the LDC, compared to the respective controls. A few spots corresponding to proteolytic products could be also identified in the LDC samples. According to previous reports on the functional significance of these variations (GonzálezCamacho and Medina, 2005, 2006), these differences in the span of nucleolin isoforms throughout the $\mathrm{pH}$ range correspond to differences in the phosphorylation state of the protein. It is known that the activity of nucleolin in the regulation of pre-rRNA synthesis and processing in the nucleolus, which takes place at different steps of the process, depends on its phosphorylation and proteolysis (Warrener and Petryshyn, 1991). Interestingly, our results clearly show that nucleolin is a target of the gravitational stress, playing a role in the cellular response affecting ribosome biogenesis/cell growth, but the changes observed after a short altered gravity treatment were mainly caused by post-translational modifications of the protein (phosphorylation/dephosphorylation), and not by changes in gene expression, which are eventually detected only when the treatments of altered gravity extend for longer periods of time (unpublished results). It appears that, in this case, it is easier and quicker to respond to the environmental change by modifying a component already present in the cell than to re-arrange the complex machinery of the regulation of gene expression.

Therefore, the full picture of the early response to altered gravity in terms of ribosome biogenesis/cell growth is that a partial response at the molecular level (proteomic rather than transcriptomic) is accompanied by a partial phenotypical response, detectable at the subcellular level (size and structure of the nucleolus), but not in terms of a significant change in the cell size, which is only detectable after longer times of exposure to altered gravity (Matía et al., 2010; Manzano et al., 2013). Therefore, the change in the nucleolus is part of the early response to gravity alteration affecting cell growth and precedes the effect at the whole cell level.

According to our results, changes in cell growth and proliferation caused by altered gravity in proliferating cells in culture in vitro follow the same trend as previously described for root meristematic cells. This occurs despite the fact that the aggregation of the callus cells does not constitute an actual tissue, 
unlike what happens in the root meristem. As far as we know, there are no data on a possible mechanism of gravity sensing and response on Arabidopsis undifferentiated cells. Previous papers only report the existence of some sort of responses to microgravity in these cellular systems, without investigating the mechanism, in Nicotiana (Sieberer et al., 2009) and Brassica (Rasmussen et al., 1994), but it is clear that every plant cell has elements that could be sensitive to a mechanical stimulation, such as the gravity alteration. The cell wall, the plasma membrane and the cytoskeleton could be good candidates to play a role in this process (Staves et al., 1997; Hoson et al., 2005, 2010) (see Herranz and Medina, 2014 for a hypothesis).

In conclusion, the short-term incubation of a plant cell callus culture of Arabidopsis thaliana in different devices for simulated microgravity and hypergravity has allowed the identification of morphofunctional types of the nucleolus, which have been correlated with the cell growth/cell proliferation status. These nucleolar types have a potential applicability as environmental stress sensors or as pathological markers. Moreover, we have found that altered gravity induces early changes in cell cycle progression and regulation, as well as in the rate of ribosome biogenesis, which are related to post-translational modification of the nucleolar protein nucleolin. These changes, essentially similar to those previously described for seedlings, occur in the absence of any known specialized mechanism for gravity perception in cell cultures in vitro. Therefore, intracellular mechanisms of sensing and transduction of the gravity signals should operate in undifferentiated cells.

\section{AUTHOR CONTRIBUTIONS}

The conception and design of the work was mainly the responsibility of FJM, with the participation of RH and JVL. The acquisition of data was the responsibility of AIM, RH, and AM, with the participation of JVL. Analysis and interpretation of data, drafting the work, critical revision for important intellectual content and final approval of the version to be published was the responsibility of all five co-authors. All of them are in agreement to be accountable for all aspects of the work in ensuring that

\section{REFERENCES}

Barjaktarovic, Z., Nordheim, A., Lamkemeyer, T., Fladerer, C., Madlung, J., and Hampp, R. (2007). Time-course of changes in amounts of specific proteins upon exposure to hyper-g, 2-D clinorotation, and 3-D random positioning of Arabidopsis cell cultures. J. Exp. Bot. 58, 4357-4363. doi: 10.1093/jxb/erm302

Barjaktarovic, Z., Schutz, W., Madlung, J., Fladerer, C., Nordheim, A., and Hampp, R. (2009). Changes in the effective gravitational field strength affect the state of phosphorylation of stress-related proteins in callus cultures of Arabidopsis thaliana. J. Exp. Bot. 60, 779-789. doi: 10.1093/jxb/ern324

Baserga, R. (2007). Is cell size important? Cell Cycle 6, 814-816. doi: 10.4161/cc.6.7.4049

Beemster, G. T. S., and Baskin, T. I. (1998). Analysis of cell division and elongation underlying the developmental acceleration of root growth in Arabidopsis thaliana. Plant Physiol. 116, 1515-1526. doi: 10.1104/pp.116.4.1515

Bernstein, K. A., and Baserga, S. J. (2004). The small subunit processome is required for cell cycle progression at G1. Mol. Biol. Cell 15, 5038-5046. doi: 10.1091/mbc.E04-06-0515 questions related to the accuracy or integrity of any part of the work are appropriately investigated and resolved.

\section{FUNDING}

AIM and AM were supported by the Spanish FPI fellowship program. RH was supported by a Spanish Science and Technology (Especialización en Organismos Internacionales)/CDTI scholarship (ESA Spanish trainee program) and also supported by a CSIC JAE-Doc contract. This work was supported by Grants from the Spanish "Plan Nacional de Investigación Científica y Desarrollo Tecnológico” (Ministerio de Economía y Competitividad, Spain), Refs. AYA2010-11834-E and AYA2012-33982 to FJM and AYA2009-07792-E to RH and by the access to the Ground Based Facilities: ESA SEGMGSPE_Ph1 Project (contract number 4200022650) to JVL, FJM, and RH.

\section{ACKNOWLEDGMENTS}

We thank Dr. J. Sáez-Vásquez (University of Perpignan, France) for the generous gift of anti-nucleolin antibody. The present research would not have been possible without the technical support from the section TEC-MMG at ESTEC, especially Mr. Allan Dowson, Mr. Robert Lindner and Mrs. Jutta Krause, and the technical personnel of CIB-CSIC, especially Dr. Pedro Lastres and Mrs. Mercedes Carnota.

\section{SUPPLEMENTARY MATERIAL}

The Supplementary Material for this article can be found online at: http://journal.frontiersin.org/article/10.3389/fspas. 2016.00002

Data Sheet 1 | Tables with quantitative expression of cell cycle genes. Both cell cycle core machinery (bold) and cell cycle related genes induced or repressed under altered gravity conditions numbers are shown (provided as an EXCEL sheet 1 and 2). Gene expression fold changes for RPM and LDC vs. control of the 31 genes with significant alterations under $2 g$ conditions using a limma $p$-value $<$ 0.01 by FIESTA viewer v.1.0. Other statistical tests have been provided (limma, limma FDR and Rankprod).Sheet 3 (in the same document) elaborates quantitative PCR numbers represented in Figure 5. Mean \pm standard deviation values for 3 replicates are provided for control and experimental conditions.

Bernstein, K. A., Bleichert, F., Bean, J. M., Cross, F. R., and Baserga, S. J. (2007). Ribosome biogenesis is sensed at the start cell cycle checkpoint. Mol. Biol. Cell 18, 953-964. doi: 10.1091/mbc.E06-06-0512

Borst, A. G., and Van Loon, J. J. W. A. (2009). Technology and developments for the random positioning machine, RPM. Microgr. Sci. Technol. 21, 6. doi: 10.1007/s12217-008-9043-2

Cerdido, A., and Medina, F. J. (1995). Subnucleolar location of fibrillarin and variation in its levels during the cell cycle and during differentiation of plant cells. Chromosoma 103, 625-634. doi: 10.1007/BF00357689

Colón-Carmona, A., You, R., Haimovitch-Gal, T., and Doerner, P. (1999). Technical advance: spatio-temporal analysis of mitotic activity with a labile cyclin-GUS fusion protein. Plant J. 20, 503-508. doi: 10.1046/j.1365313x.1999.00620.x

Darbelley, N., Driss-École, D., and Perbal, G. (1989). Elongation and mitotic activity of cortical cells in lentil roots grown in microgravity. Plant Physiol. Biochem. 27, 341-347.

De Veylder, L., Beeckman, T., and Inzé, D. (2007). The ins and outs of the plant cell cycle. Nat. Rev. Mol. Cell Biol. 8, 655-665. doi: 10.1038/nrm2227 
Doerner, P. (2008). "Signals and mechanisms in the control of plant growth," in Plant Growth Signaling, eds L. Bögre and G. Beemster (Berlin; Heidelberg: Springer), 1-23. doi: 10.1007/7089_2007_142

Driss-Ecole, D., Legué, V., Carnero-Diaz, E., and Perbal, G. (2008). Gravisensitivity and automorphogenesis of lentil seedling roots grown on board the International Space Station. Physiol. Plantarum 134, 191-201. doi: 10.1111/j.1399-3054.2008.01121.x

Fengler, S., Spirer, I., Neef, M., Ecke, M., Nieselt, K., and Hampp, R. (2015). A whole-genome microarray study of Arabidopsis thaliana semisolid callus cultures exposed to microgravity and nonmicrogravity related spaceflight conditions for 5 days on board of shenzhou 8. BioMed Res. Int. 2015:547495. doi: 10.1155/2015/547495

González-Camacho, F., and Medina, F. J. (2004). Identification of specific plant nucleolar phosphoproteins in a functional proteomic analysis Proteomics 4, 407-417. doi: 10.1002/pmic.200300645

González-Camacho, F., and Medina, F. J. (2005). The nucleolar structure and nucleolar proteins as indicators of cell proliferation events in plants. J. Appl. Biomed. 3, 167-174. Available online at: http://jab.zsf.jcu.cz//3_4/medina.pdf

González-Camacho, F., and Medina, F. J. (2006). The nucleolar structure and the activity of nucleolin-like protein NopA100 during the cell cycle in proliferating plant cells. Histochem. Cell Biol. 125, 139-153. doi: 10.1007/s00418-005-0081-1

Herranz, R., Anken, R., Boonstra, J., Braun, M., Christianen, P. C. M., Geest, M. D., et al. (2013a). Ground-based facilities for simulation of microgravity: organismspecific recommendations for their use, and recommended terminology. Astrobiology 13, 1-17. doi: 10.1089/ast.2012.0876

Herranz, R., Manzano, A. I., Van Loon, J. J. W. A., Christianen, P. C. M., and Medina, F. J. (2013b). Proteomic signature of Arabidopsis cell cultures exposed to magnetically induced hyper- and microgravity environments. Astrobiology 13, 217-224. doi: 10.1089/ast.2012.0883

Herranz, R., and Medina, F. J. (2014). Cell proliferation and plant development under novel altered gravity environments. Plant Biol. 16, 23-30. doi: $10.1111 / \mathrm{plb} .12103$

Hoson, T., Matsumoto, S., Soga, K., and Wakabayashi, K. (2010). Cortical microtubules are responsible for gravity resistance in plants. Plant Signal. Behav. 5, 752-754. doi: 10.4161/psb.5.6.11706

Hoson, T., Saito, Y., Soga, K., and Wakabayashi, K. (2005). Signal perception, transduction, and response in gravity resistance. Another graviresponse in plants. Adv. Space Res. 36, 1196-1202. doi: 10.1016/j.asr.2005.04.095

Inzé, D., and De Veylder, L. (2006). Cell cycle regulation in plant development. Annu. Rev. Genet. 40, 77-105. doi: 10.1146/annurev.genet.40.110405.090431

Kimbrough, J. M., Salinas-Mondragon, R., Boss, W. F., Brown, C. S., and Sederoff, H. W. (2004). The fast and transient transcriptional network of gravity and mechanical stimulation in the Arabidopsis root apex. Plant Physiol. 136, 2790-2805. doi: 10.1104/pp.104.044594

Klaus, D. M., Schatz, A., Neubert, J., Höfer, M., and Todd, P. (1997). Escherichia coli growth kinetics: a definition of "functional weightlessness" and a comparison of clinostat and space flight results. Naturwissenschaften 143, 7.

Kraft, T. F., van Loon, J. J., and Kiss, J. Z. (2000). Plastid position in Arabidopsis columella cells is similar in microgravity and on a random-positioning machine. Planta 211, 415-422. doi: 10.1007/s004250000302

Legué, V., Yu, F., Driss-École, D., and Perbal, G. (1996). Effects of gravitropic stress on the development of the primary root of lentil seedlings grown in space. J. Biotechnol. 47, 129-135. doi: 10.1016/0168-1656(96)01356-9

Li, C., Potuschak, T., Colón-Carmona, A., Gutiérrez, R. A., and Doerner, P. (2005). Arabidopsis TCP20 links regulation of growth and cell division control pathways. Proc. Natl. Acad. Sci. U.S.A. 102, 12978-12983. doi: 10.1073/pnas.0504039102

Manzano, A. I., Herranz, R., Van Loon, J., and Medina, F. J. (2012b). Cell growth and cell proliferation decoupling under hypergravity environments induced by centrifugation. Microgravity Sci. Technol. 24, 373-381. doi: 10.1007/s12217012-9301-1

Manzano, A. I., Larkin, O., Dijkstra, C., Anthony, P., Davey, M., Eaves, L., et al. (2013). Meristematic cell proliferation and ribosome biogenesis are decoupled in diamagnetically levitated Arabidopsis seedlings. BMC Plant Biol. 13:124. doi: 10.1186/1471-2229-13-124

Manzano, A. I., Matía, I., González-Camacho, F., Carnero-Díaz, E., Van Loon, J. J. W. A., Dijkstra, C., et al. (2009). Germination of Arabidopsis seed in space and in simulated microgravity: alterations in root cell growth and proliferation. Microgr. Sci. Technol. 21, 293-297. doi: 10.1007/s12217-0089099-z

Manzano, A., van Loon, J., Christianen, P., Gonzalez-Rubio, J., Medina, F. J., and Herranz, R. (2012a). Gravitational and magnetic field variations synergize to cause subtle variations in the global transcriptional state of Arabidopsis in vitro callus cultures. BMC Genomics 13:105. doi: 10.1186/1471-2164-13-105

Matía, I., González-Camacho, F., Herranz, R., Kiss, J. Z., Gasset, G., van Loon, J. J. W. A., et al. (2010). Plant cell proliferation and growth are altered by microgravity conditions in spaceflight. J. Plant Physiol. 167, 184-193. doi: 10.1016/j.jplph.2009.08.012

Matía, I., González-Camacho, F., Marco, R., Kiss, J. Z., Gasset, G., Van Loon, J. J. W. A., et al. (2007). The "root" experiment of the "cervantes" Spanish Soyuz Mission: cell proliferation and nucleolar activity alterations in Arabidopsis roots germinated in real or simulated microgravity. Microgr. Sci. Technol. 19, 128-132. doi: 10.1007/BF02919467

Mayer, C., and Grummt, I. (2005). Cellular stress and nucleolar function. Cell Cycle 4, 1036-1038. doi: 10.4161/cc.4.8.1925

Medina, F. J., Cerdido, A., and de Cárcer, G. (2000). The functional organization of the nucleolus in proliferating plant cells. Eur. J. Histochem. 44, 117-131.

Menges, M., and Murray, J. A. (2006). Synchronization, transformation, and cryopreservation of suspension-cultured cells. Methods Mol. Biol. 323, 45-61. doi: 10.1385/1-59745-003-0:45

Merkys, A. J., Laurinavicius, R. S., and Svegzdiene, D. V. (1984). Plant growth, development and embryogenesis during Salyut-7 flight. Adv. Space Res. 4, 55-63. doi: 10.1016/0273-1177(84)90224-2

Mizukami, Y. (2001). A matter of size: developmental control of organ size in plants. Curr. Opin. Plant Biol. 4, 533-539. doi: 10.1016/S1369-5266(00)00212-0

Moreno Díaz de la Espina, S., Medina, F. J., and Risueño, M. C. (1980). Correlation of nucleolar activity and nucleolar vacuolation in plant cells. Eur. J. Cell Biol. $22,724-729$.

Moseyko, N., Zhu, T., Chang, H. S., Wang, X., and Feldman, L. J. (2002). Transcription profiling of the early gravitropic response in Arabidopsis using high-density oligonucleotide probe microarrays. Plant Physiol. 130, 720-728. doi: $10.1104 /$ pp.009688

Paul, A.-L., Zupanska, A. K., Ostrow, D. T., Zhang, Y., Sun, Y., Li, J.-L., et al. (2012). Spaceflight transcriptomes: unique responses to a novel environment. Astrobiology 12, 40-56. doi: 10.1089/ast.2011.0696

Petricka, J. J., and Nelson, T. M. (2007). Arabidopsis nucleolin affects plant development and patterning. Plant Physiol. 144, 173-186. doi: 10.1104/pp.106.093575

Pontvianne, F., Matía, I., Douet, J., Tourmente, S., Medina, F. J., Echeverría, M., et al. (2007). Characterization of AtNUC-L1 reveals a central role of nucleolin in nucleolus organization and silencing of AtNUC-L2 gene in Arabidopsis. Mol. Biol. Cell 18, 369-379. doi: 10.1091/mbc.E06-08-0751

Raska, I., Shaw, P. J., and Cmarko, D. (2006). Structure and function of the nucleolus in the spotlight. Curr. Opin. Cell Biol. 18, 325-334. doi: 10.1016/j.ceb.2006.04.008

Rasmussen, O., Bondar, R. L., Baggerud, C., and Iversen, T. H. (1994). Development of plant protoplasts during the IML-1 mission. Adv. Space Res. 14, 189-196. doi: 10.1016/0273-1177(94)90403-0

Risueño, M. C., and Medina, F. J. (1986). "The nucleolar structure in plant cells," in Cell Biology Reviews (RBC), Vol. 7, ed E. Barberá-Guillem (Leioa; Vizcaya: University of the Basque Country-Springer International), 1-154.

Sáez-Vásquez, J., Caparros-Ruiz, D., Barneche, F., and Echeverría, M. (2004). A plant snoRNP complex containing snoRNAs, fibrillarin, and nucleolin-like proteins is competent for both rRNA gene binding and pre-rRNA processing in vitro. Mol. Cell Biol. 24, 7284-7297. doi: 10.1128/MCB.24.16.7284-72 97.2004

Sáez-Vásquez, J., and Medina, F.J. (2008). "The plant nucleolus," in Advances in Botanical Research, Vol. 47, eds J. C. Kader and M. Delseny. (San Diego, CA: Elsevier), 1-46.

Shen-Miller, J., and Hinchman, R. R. (1995). Nucleolar transformation in plants grown on clinostats. Protoplasma 185, 194-204. doi: 10.1007/BF01272860

Sieberer, B. J., Kieft, H., Franssen-Verheijen, T., Emons, A. M. C., and Vos, J. W. (2009). Cell proliferation, cell shape, and microtubule and cellulose microfibril organization of tobacco BY-2 cells are not altered by exposure to near weightlessness in space. Planta 230, 1129-1140. doi: 10.1007/s00425-0091010-7 
Sobol, M., González-Camacho, F., Rodríguez-Vilariño, V., Kordyum, E. L., and Medina, F. J. (2005). Clinorotation influences rDNA and NopA100 localization in nucleoli. Adv. Space Res. 36, 1254-1262. doi: 10.1016/j.asr.2005.05.072

Sobol, M., González-Camacho, F., Rodríguez-Vilariño, V., Kordyum, E., and Medina, F. J. (2006). Subnucleolar location of fibrillarin and NopA64 in Lepidium sativum root meristematic cells is changed in altered gravity. Protoplasma 228, 209-219. doi: 10.1007/s00709-006-0157-3

Srivastava, M., and Pollard, H. B. (1999). Molecular dissection of nucleolin's role in growth and cell proliferation: new insights. FASEB J. 13, 1911-1922.

Staves, M. P., Wayne, R., and Leopold, A. C. (1997). The effect of the external medium on the gravitropic curvature of rice (Oryza sativa, Poaceae) roots. Amer. J. Bot. 84, 1522-1529. doi: 10.2307/2446613

Testillano, P. S., González-Melendi, P., Ahmadian, P., and Risueño, M. C. (1995). The methylation-acetylation method: an ultrastructural cytochemistry for nucleic acids compatible with immunogold studies. J. Struct. Biol. 114, 123-139.

Van Leene, J., Hollunder, J., Eeckhout, D., Persiau, G., Van De Slijke, E., Stals, H., et al. (2010). Targeted interactomics reveals a complex core cell cycle machinery in Arabidopsis thaliana. Mol. Syst. Biol. 6, 397. doi: 10.1038/msb.2010.53

Van Loon, J. J. W. A. (2007). Some history and use of the random positioning machine, RPM, in gravity related research. Adv. Space Res. 39, 1161-1165. doi: 10.1016/j.asr.2007.02.016

Van Loon, J. J. W. A., Tranck, E., Van Nieuwenhoven, F. A., Snoeckx, L. H. E. H., De Jong, H. A., and Wubbels, R. J. (2005). A brief overview of animal hypergravity studies. J. Gravit. Physiol. 12, 6.
Van Loon, J., Krause, J., Cunha, H., Goncalves, J., Almeida, H., and Schiller, P. (2008). "The large diameter centrifuge, LDC, for life and physical sciences and technology," in Proceedings of the Life In Space For Life On Earth Symposium (Angers), 22-27.

Warrener, P., and Petryshyn, R. (1991). Phosphorylation and proteolytic degradation of nucleolin from 3T3-F442A cells. Biochem. Biophys. Res. Commun. 180, 716-723. doi: 10.1016/S0006-291X(05) 81124-6

Yu, F., Driss-École, D., Rembur, J., Legu,é, V., and Perbal, G. (1999). Effect of microgravity on the cell cycle in the lentil root. Physiol. Plantarum 105, 171-178. doi: 10.1034/j.1399-3054.1999. 105125.x

Conflict of Interest Statement: The authors declare that the research was conducted in the absence of any commercial or financial relationships that could be construed as a potential conflict of interest.

Copyright (๑) 2016 Manzano, Herranz, Manzano, van Loon and Medina. This is an open-access article distributed under the terms of the Creative Commons Attribution License (CC BY). The use, distribution or reproduction in other forums is permitted, provided the original author(s) or licensor are credited and that the original publication in this journal is cited, in accordance with accepted academic practice. No use, distribution or reproduction is permitted which does not comply with these terms. 